\title{
[[HEADER SECTION]]
}

\section{Clinical skills}

How to perform basic first aid

\section{[[SUMMARY SECTION]]}

\author{
Authors \\ Rationale [100 -150 words]
}

This article is written to explain the principles in relation to basic first aid.

- First aid is the provision of immediate medical assistance to an ill or injured person until definitive medical treatment can be accessed.

- First aid can and does save lives and it is essential therefore that nurses update themselves with basic knowledge.

- First aid consists of a series of simple, potentially life-saving steps that an individual can perform with minimal equipment

- Nurses are accountable for all their actions and any omissions when caring for patients, and should understand the basic principles of first aid

- Some nurses may not feel they have the necessary skills or experience to deal with an emergency outside of their normal work setting.

- Although it is not a legal requirement to respond to a situation outside of work, there is a professional duty to respond and provide care.

\section{Contributing to Clinical skills}

Nursing Standard encourages author contributions to the Clinical Skills series. Please email How.to@rcnpublishing.co.uk with a synopsis of your idea. All submissions are subject to doubleblind peer-review and checked for plagiarism using automated software.

\section{[[MAIN TEXT SECTION]]}

\section{Preparation and equipment}

- If a first aid bag / kit are available they may contain the following: Triangular bandage, nonadherent simple dressing, surgical tape, burn dressing, conforming bandage, non-sterile gloves and foil blanket.

- If there is no equipment available then the nurse may need to improvise with materials at the scene: for example a scarf can be used as a sling; cling film can be used for burns as a temporary burns dressing.

- Knowledge of personal safety and protecting yourself from exposure to risks, such as bodily fluids, is essential to prevent harm to you. 


\section{Initial Assessment}

1. Personal safety: Check the area is safe for you to respond, for example: no traffic or falling debris that may cause you to get injured. Look for environmental hazards such as toxic substances if a spillage has occurred, pets in a home or personal safety in a quiet street when dark. If there are signs of bodily fluids or bleeding then use gloves if available to protect you before attending to the victim. Plastic bags could be used when gloves not available.

2. Initial assessment: Use the $A B C$ principles (Airway, Breathing, and Circulation) to identify any life threatening problems. If you need medical assistance then call 999 stating you are a nurse and use the $A B C$ steps to communicate your findings.

3. Unresponsive: If the person appears to be unresponsive then apply pressure to the trapezius muscle: applying pressure using and thumb and two fingers squeeze this muscle, and ask them to open their eyes. If they are breathing and show signs of life then place in the recovery position (see fig 1) unless they appear to have injuries that prevent you from moving them, however their airway must be clear and takes priority. Ensure their airway is clear and maintain this until help arrives.

4. No sign of life: Call for help and follow the Basic Life Support guidelines (Resuscitation Council, 2010)

\section{Further assessment of injuries}

5. Wound assessment: Look for any visible signs of bleeding. If there is an obvious wound that is actively bleeding with no visible foreign body, cover with a non-adherent dressing and secure with a bandage to apply direct pressure and elevate above the level of the heart if able. If the bleeding continues and the person is showing signs of shock such as; pale, weak pulse, sweating, feeling thirsty or nauseous, then ensure they are laid down, kept warm and if possible elevate their legs until medical help arrives (call 999).

6. Check that the person has sensation and a pulse distal to the pressure dressing to ensure this has not been placed too tight.

7. If the wound has a foreign body protruding (or bone) then apply the dressing around the foreign object and pad securely to prevent the foreign object from moving. Elevate as before and reassess circulation and sensation distal to the dressing.

8. Possible limb fractures: If there are signs of injury to a limb such as pain, swelling, or deformity then restrict movement by splinting the affected limb. If this is an arm, then consider using the triangular bandage and elevate in a broad arm sling (see fig 2) asking the person to support the limb while applying this.

9. If the deformity or pain relates to a lower limb, then to minimise pain further injury restrict movement by avoiding use of the leg. Consider using the unaffected leg as a splint and using the bandage to secure both legs (see fig 3 ) if an upper leg fracture is suspected. If a lower leg fracture is suspected then keep in a stable position and do not move if there is obvious deformity; assess circulation distal to the fracture site: as well as sensation, pulse and colour and call for help.

10. If there is no deformity however the person reports pain and inability to weight bear then elevate the lower limb if possible and take them to a medical facility for further assessment such as: a walk in centre; urgent care centre or emergency department.

11. Burns and scalds: approach with care. Stop the burning process by removing the heat source, turn off the power if electricity is involved, remove the victim's clothing (unless it is stuck to the skin) and jewellery.

12. Cool the area that has been burnt, using running cool/tepid water for 10-30 minutes: watch that you do not over-cool the person if a large area has been burnt and keep the person warm.

13. Once cooled, use a clean dry dressing or, if to hand, cling film over the burn to protect the skin. Do not wrap the cling film around a limb as this might act like a tourniquet thus compounding the problem. 
14. For chemical burns, wear protective gloves and ensure the patient attends hospital. Elevate the affected area if oedema and swelling are present. If information is available for the chemical involved follow the instructions given.

15. Most minor burns can be managed at home, if you are at all concerned request the patient attend hospital for further assessment and specialist treatment.

Figure 1 - The recovery position

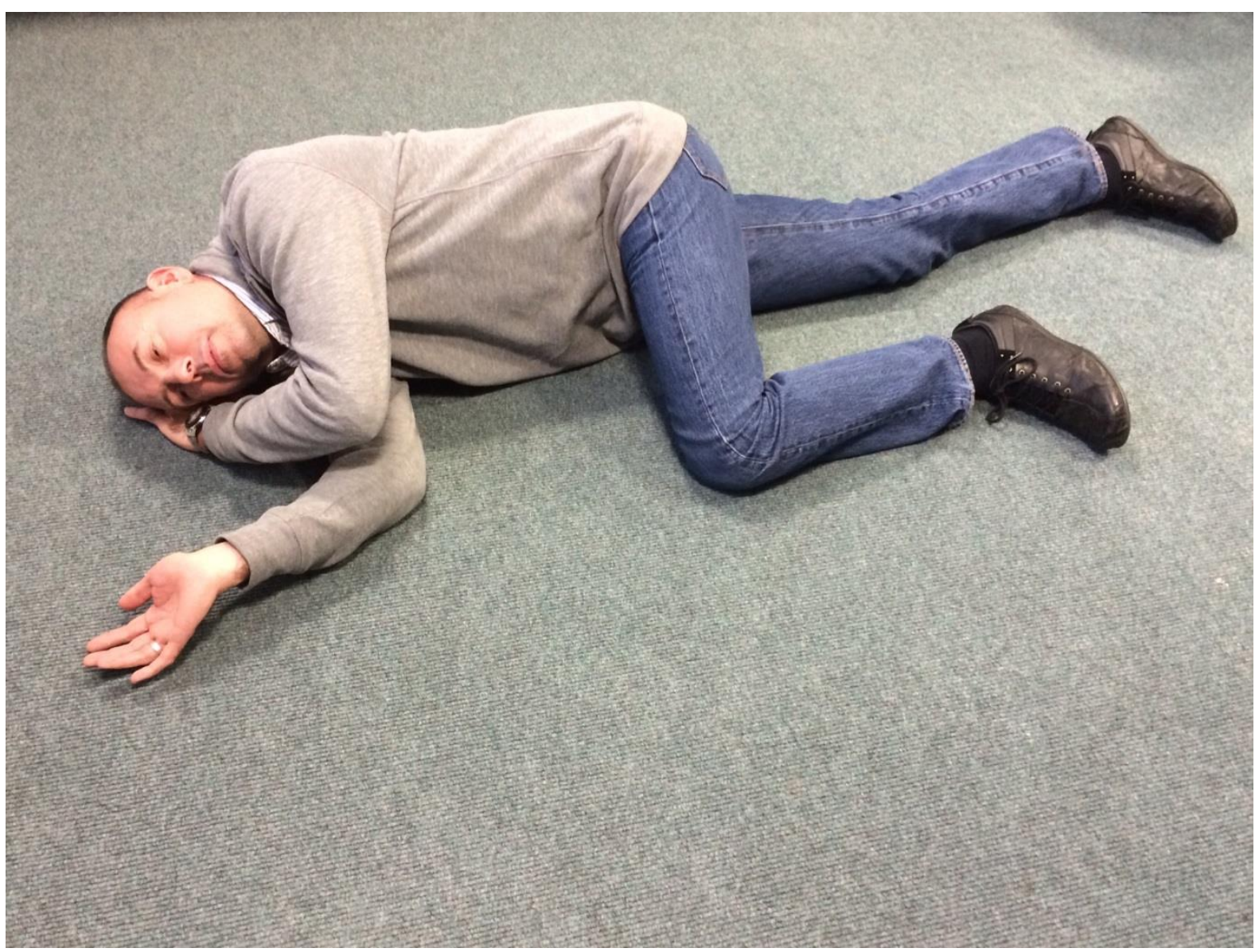


Figure 2 - Broad arm sling

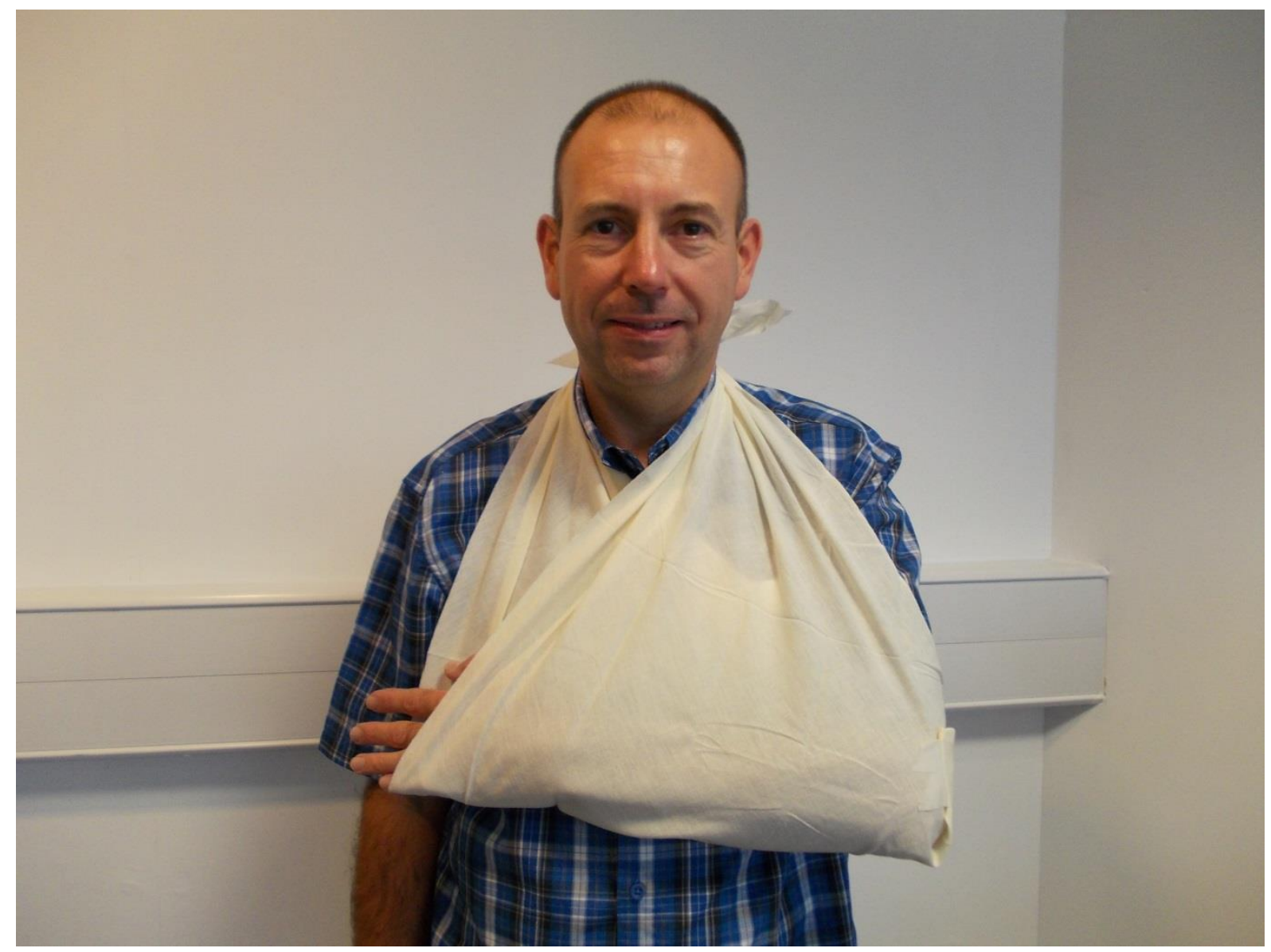




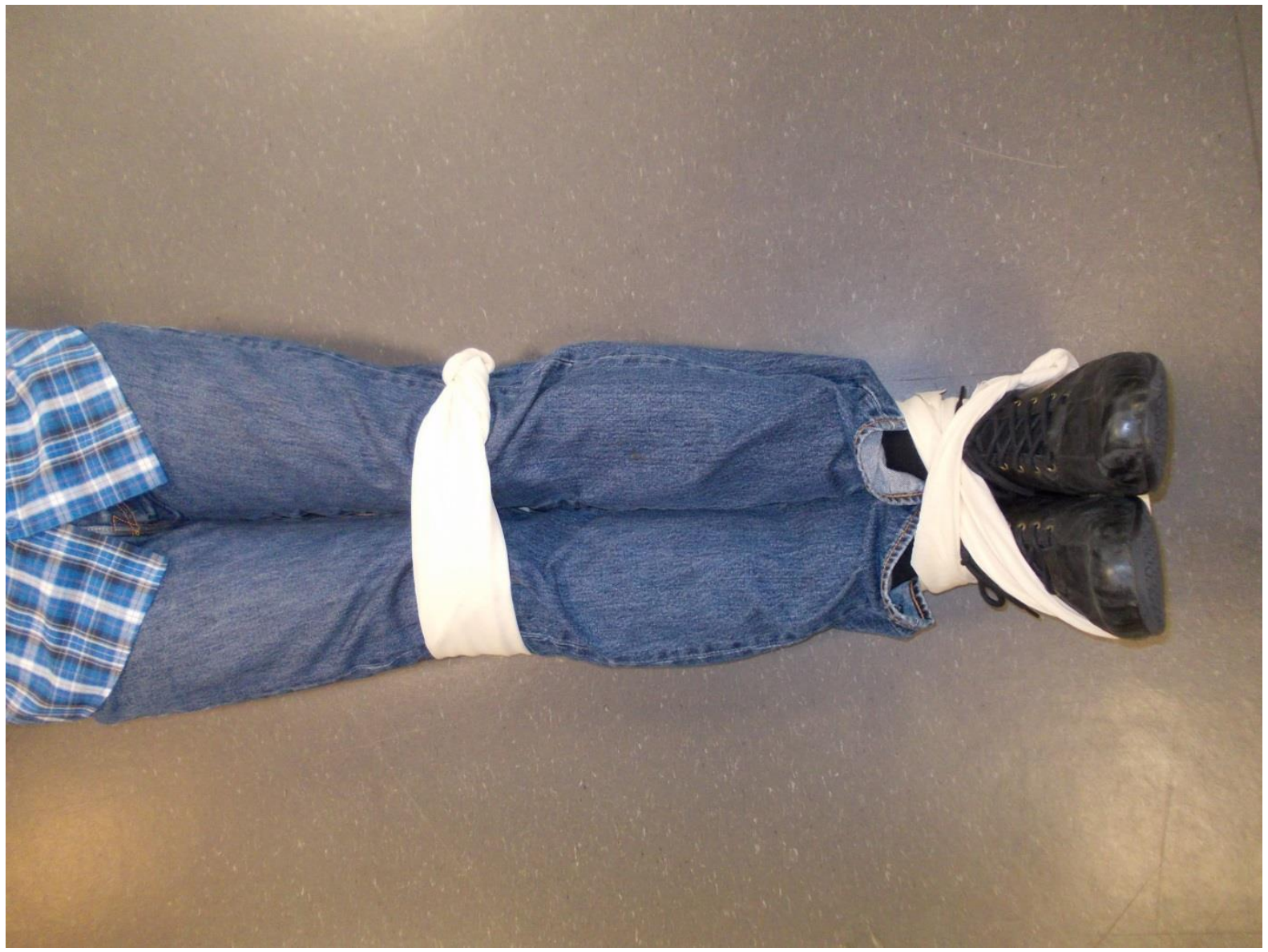

\section{Evidence base}

The principles of first aid are to preserve life and to limit the deterioration of the condition. The ethical principles of beneficence and non-maleficence apply to any first aid situation and therefore require the nurse to undertake a thorough assessment before giving any treatment to a victim.

Nurses should only perform those interventions in which they are competent in and act according to their professional code (NMC, 2010; Dimond, 2008). A systematic approach to the assessment should be undertaken to ensure that any life threatening conditions can be treated first using $A B C$ (Airway, Breathing, Circulation) (Resuscitation Council, 2010) even with the conscious victim. If required medical assistance should be summoned once an assessment has been undertaken.

Preservation of life requires attention to personal safety and follows the principles of basic life support and then the control of major bleeding. If bleeding or bodily fluids are present then the nurse should protect themselves with gloves found in a typical first aid kit, or improvise with plastic bags. Controlling blood loss with direct pressure and elevation will minimise shock which can result from severe blood loss. Encouraging the victim to lie down will also reduce blood flow to the wound minimising blood loss. Covering open wounds with a non-adherent sterile dressing will protect from infection and begin to promote natural healing. If direct pressure is insufficient to reduce the bleeding then indirect pressure may be applied to a pressure point above the bleeding artery. 
Pressure should not be applied for more than ten minutes and medical assistance should be sought (St John Ambulance et al, 2014). If the victim's level of consciousness begins to deteriorate then revert back to assessing Airway and Breathing and consider placing them in the recovery position while waiting for medical assistance, as this will help manage their airway.

In most situations that require first aid there will be no life-threatening danger, however a minor injury or illness can still create significant pain and anxiety and requires the nurse to adopt a calm and reassuring in manner in order to identify what is wrong, and to give the most appropriate treatment for that situation. Fractures and burns can be extremely painful and distressing and require urgent assessment and appropriate treatment to minimise further damage or pain to the victim.

If a broken bone is suspected the aim is to support and splint with either a sling or the unaffected limb if possible. Minimising shock is a priority as up to $1500 \mathrm{ml}$ of blood can be lost from a fracture to the femur as bleeding can occur from the disruption of vessels close to bones (TNCC, 2014). If the fracture is open - there is a break through the skin (the bone may or not be visible) then a priority is to minimise infection and to cover with a sterile dressing. Splinting, reducing movement and not using the limb will reduce pain and reduce the risk of movement of an unstable fracture and circulatory compromise. After undertaking any intervention reassessment of neurovascular status should be carried out to ensure this has not changed.

Literature

References [10-15 max]

1. Dimond, B. (2008) Legal aspects of Nursing (5th edtn) Essex, Pearson Education Ltd.

2. Emergency Nurses Association (2014)Trauma Nursing Core Course provider manual (7th edtn) ENA

3. Enoch, S., Roshan, A., Shah, M. (2009) Emergency and early management of burns and scalds. BMJ. Apr 8;338:b1037.

4. NHS Videos: The recovery position http://www.nhs.uk/video/pages/recoveryposition.aspx

5. Nursing and Midwifery Council (2010) The code: standards of conduct, performance and ethics for nurses and midwives. [online] http://www.nmcuk.org/Documents/Standards/nmcTheCode StandardsofConductPerformanceAndEthicsF orNursesAndMidwives LargePrintVersion.P $\underline{\mathrm{DF}}$

6. Resuscitation Council (2010) Chapter 2: Basic Life Support. [online] https://www.resus.org.uk/pages/bls.pdf

7. St John Ambulance et al (2014) First Aid Manual (10 ${ }^{\text {th }}$ edtn). London. Dorling, Kindersley.
Further reading and useful links [5 max]

1. British Red Cross http://www.redcross.org.uk/en/Wha t-we-do/First-aid/First-aid-training

2. St John Ambulance http://www.sja.org.uk/sja/first-aidadvice.aspx

3. Patient.co.uk - Fractures http://www.patient.co.uk/doctor/for earm-injuries-and-fracture

4. Patient.co.uk - Burns http://www.patient.co.uk/doctor/Bu rns-Assessment-andManagement.htm

5. Video - burns and scalds http://www.patient.co.uk/video/Deal ing-with-Burns-and-Scalds.htm 


\section{Reflective activity}

1. What further reading or resources do you need to consider in order to feel confident when dealing with a first aid situation??

2. How could you use this resource to educate your colleagues, family and friends?

\section{[[FOOTER SECTION]]}

Please note that information provided by Nursing Standard is not sufficient to make the reader competent to perform the task. All clinical skills should be formally assessed at the bedside by a nurse or nursing student's peers, educators and mentors. It is all nurses' responsibility to ensure their practice remains up to date and reflects the latest evidence. [DOCUMENT ENDS] 